\title{
Speed Estimation of Induction Motor at Low and Zero Speed using High Frequency Signal Injection for Rotor Slot Harmonics Detection
}

\author{
S. Damkhi ${ }^{1}$, M.S. Nait Said ${ }^{2}$ and N. Nait Said ${ }^{1}$ \\ ${ }^{1}$ Department of Electrical Engineering \\ L.S.P.I.E., Batna University \\ Constantine Road - Fesdis, 05078 Batna (Algeria) \\ Phone/Fax number: +213 332302 22, e-mail: sihemd@ymail.com,n_naitsaid@yahoo.com \\ ${ }^{2}$ Faculty of Technology University of Batna 1, Chahid Boukhlouf street Mohamed el-Hadi, Banta 05000 \\ medsnaitsaid@yahoo.fr
}

\begin{abstract}
Rotor position estimation based on high frequency signal injection method represents the interesting way to provide the high performances of the AC drives sensorless controlled at low or near zero speed range. So, this method requires the existence of saliencies inside the IM particularly the presence of the slots where their design constitutes the main advantageous to exploit its effect for rotor speed monitoring. First, the present paper exposes a model of the induction machine including slotting effects which it can be exploited in order to extract the harmonic saliency created by rotor slotting. Second, the high frequency signal injection method is used in order to allow tracking the characteristic harmonic saliency due to rotor slotting from which the rotor position and speed may be estimated. A High frequency voltage signal injection creates a high frequency current modulated by the saliencies presented inside the machine. To extract information about rotor position, the resulting stator current treads to heterodyning process to eliminate the disturbance components and subsequently the rotor position may be extracted by a closed-loop observer. Simulation results are shown in order to verify the validity of the proposal and to confirm the effectiveness of estimation method at zero frequency.
\end{abstract}

\section{Key words}

Induction Machine (IM), High Frequency (HF), Closed Loop Observer, Saliencies, Sensorless Control.

\section{Introduction}

Sensorless control techniques for AC machines that rely on the rated excitation frequency have been shown to be able providing high-performance control, e.g., fieldoriented control and direct torque control, in the medium to high-speed range. However, as the speed decreases, the performance of these methods decreases and eventually be unsuccessful in very low-speed range and/or for dc excitation [1]. At zero frequency the sensorless speed operation may be only possible using signal injection methods. These methods are used to track spatial saliencies of the induction machine by the superimposing of HF signal on the stator voltage supply. Injecting the HF voltage to fundamental supply, the flux/rotor position can be determined by evaluating the current response. This current consists of two components where one of these components called negative sequence component is modulated by all spatial saliencies that are affecting the leakage inductance.

The sources of saliencies are diverse, such as the saturation of the machine by the main flux, induced saturation, modification in opening of rotor slots and slotting effects [2]. The use of slotting effects for rotor speed estimation is the best method because it is not dependent on the machine parameters and not created by modification in rotor design.

The combination between the model including the slotting effects and the use of high frequency voltage to track the rotor saliency defines the aim of the present paper. For control applications a proper modelling of induction machine including saliencies effects is very important. In literature several kinds of models can be found. Some of these kinds of models are based on finite element analysis proposed in [3],[4]. Also other models rewritten in space state form including a stator and rotor effects may be applied in the machine control applications, especially for speed sensorless induction machine control.

The proposal is focused on the estimation of rotor position using both slotting effects and high frequency signal injection. The slotting effects are introduced in induction machine (IM) model for making the machine has rotor saliency. HF signal injection voltage is employed to track harmonic saliency due to the slotting effects and after there the rotor position may be followed and tracked from the closed-loop-observer after some conform signal treatment processing. 


\section{Saliency Tracking by HF Signal Injection}

Using the injected signal that feeds the IM with a persistent high frequency excitation $(0.5 \div 1 \mathrm{KHz})$ to track spatial saliency image is achieved in many researches [5][7]. Injected signal nature may be as voltage or current, the use of either signal is dependent on application and the nature of desired signal to obtain current/voltage. In general higher performance is possible with carrier signal voltage injection since the current regulator does not directly limit its bandwidth [8]. In case where an additional HF voltage is superimposed to stator supply, we distinguish rotating or pulsating HF voltage. Pulsating if HF voltage injected in one phase or if it consists three identical voltages. In this work we consider rotating $\mathrm{HF}$ voltage signal as additional signal. It is a balanced threephase voltage set with magnitude $V_{c}$ and frequency $w_{c}$. Using $3 \mathrm{D}$ to $2 \mathrm{D}$ transformation, we can write two orthogonal axes the rotating injected voltage as:

$$
V_{s-c}^{s}=V_{c}\left[\begin{array}{c}
\cos \left(w_{c} t\right) \\
\sin \left(w_{c} t\right)
\end{array}\right]=V_{c} e^{j w_{c} t}
$$

Because the frequency of rotating voltage is much larger than the frequency of fundamental wave, the modelling of the machine using only the stator transient inductance may be assumed as a good approximation. We can adopt, from [5] that the HF injected voltage is appreciatively compensated by a drop total flux leakage, and then the injected voltage created the HF current stator may be given by:

$$
I_{s-c}^{s} \approx \frac{\left[L_{\sigma \sigma}^{s}\right]^{-1}}{j w_{c}} V_{s-c}^{s}
$$

where, $L_{\sigma s}$ is the stator transient inductance might be as a scalar number if the saliencies effect of the IM is neglected else this parameter is described by a matrix, given next by (3) which relies the presence of the rotor saliencies position, evidently if these last exist.

Aassuming that the IM contains only the single saliency due to the interaction between rotor and stator slots, therefore the stator transient inductance matrix may be done as [5]:

$$
L_{\sigma s}^{s}=\left[\begin{array}{cc}
\sum L_{\sigma s}+\Delta L_{\sigma s} \cos \left(h \theta_{r}\right) & \Delta L_{\sigma s} \sin \left(h \theta_{r}\right) \\
\Delta L_{\sigma s} \sin \left(h \theta_{r}\right) & \sum L_{\sigma s}-\Delta L_{\sigma s} \cos (h \theta)
\end{array}\right]
$$

where

$$
\Delta L_{\sigma s}=\frac{l_{\sigma d s}-l_{\sigma q s}}{2}, \sum L_{\sigma s}=\frac{l_{\sigma d s}+l_{\sigma q s}}{2}
$$

$\Delta L_{\sigma s}$ and $\Sigma L_{\sigma s}$ present successively the differential and average of stator transient inductances of IM. $h$ is the harmonic number of the rotor slotting saliency equals to a number of the rotor slots per pole pair. In this work, the considered IM have 2 pole pairs and 28 rotor slots, then $h=14$.From (1), (2) and (3), the stator induced current leads to:

$$
\bar{I}_{s-c}^{s}=I_{C p} e^{j\left(\left(w_{c} t \frac{\pi}{2}\right)\right)}+I_{C n} e^{j\left(14 \theta_{r}-w_{c} t+\frac{\pi}{2}\right)}
$$

Last obtained formula consists in two components. First stator current component (at left) is so-called the positivesequence component proportional to the average stator transient inductance and contains no information on saliency position. Second stator current (at right) so-called negative-sequence component proportional to the differential stator transient inductance and it contains information on saliency position in its phase. Following section is consecrated to found the available model of IM including a rotor slotting saliency which might be tracked by the rotating $\mathrm{HF}$ voltage injection described in the previous section.

\section{Modeling of IM Including Stator and Rotor Slotting Effects}

The well dynamic IM Park model described in stationary reference frame is given by the following complex (2D) equations

$$
\begin{aligned}
& \bar{V}_{s}=R_{S} \bar{I}_{s}+\frac{d \bar{\Psi}_{s}}{d t} \\
& 0=R_{r} \bar{I}_{r}+\frac{d \bar{\Psi}_{r}}{d t}-j p \Omega_{r} \bar{\Psi}_{r} \\
& \bar{\Psi}_{S}=L_{S} \bar{I}_{s}+M \bar{I}_{r} \\
& \bar{\Psi}_{r}=L_{r} \bar{I}_{r}+M \bar{I}_{s} \\
& T_{e}-T_{r}=J \frac{d \Omega_{r}}{d t} \\
& T_{e}=p \operatorname{Im}\left(\bar{I}_{s} \cdot \bar{\Psi}_{s}^{*}\right)
\end{aligned}
$$

This model is available only for symmetric induction motor. When the asymmetry is introduced in IM, this model cannot be used because it unable to describe the saliencies effects which can be generated by this asymmetry. The most prominent asymmetry is a consequence of slotting effects.

In next, assume that we can extend the well known Park model to incorporate the slotting effects in rotor and stator fluxes as given below (6). Indeed, IM-slotting produces a variation in air gap and its interaction with the stator winding creates a variation in inductance [9],[10]. Assuming that only the rotor slotting effect is considered since the number of stator slots, characterizing most usual cases, which equals to three times value might be cancelled and the number of rotor slots per pole pair equals to $3 n-1$ is maintained ( $q_{r}=14$, for this data case). So the equation of stator and rotor fluxes extended from Park model becomes [11]:

$$
\begin{aligned}
& \bar{\Psi}_{s}=\left(L_{s}+L_{h} e^{-j q_{r} \theta_{r}}\right) \bar{I}_{s}+M \bar{I}_{r} \\
& \bar{\Psi}_{r}=\left(L_{r}+L_{h} e^{j q_{r} \theta_{r}}\right) \bar{I}_{r}+M \bar{I}_{s}
\end{aligned}
$$

Where

$L_{h}:$ Is the slot inductance 


\section{$q_{r}:$ Number of rotor slots per pole pair}

The currents can be extracted from (6) as follows

$$
\begin{aligned}
& \bar{I}_{s}=\left(\frac{-L_{h}}{-L_{h}^{2}+M^{2}}\right) e^{j q_{r} \theta_{r}} \bar{\Phi}_{s}+\left(\frac{M}{-L_{h}^{2}+M^{2}}\right) \bar{\Phi}_{r} \\
& \bar{I}_{r}=\left(\frac{M}{-L_{h}^{2}+M^{2}}\right) \bar{\Phi}_{s}+\left(\frac{-L_{h}}{-L_{h}^{2}+M^{2}}\right) e^{-j q_{r} \theta_{r}} \bar{\Phi}_{r}
\end{aligned}
$$

Where

$$
\begin{aligned}
& \bar{\Phi}_{s}=\bar{\Psi}_{S}-L_{S} \bar{I}_{S} \\
& \bar{\Phi}_{r}=\bar{\Psi}_{r}-L_{r} \bar{I}_{r}
\end{aligned}
$$

The block diagram of obtained model is shown in figure 1 . This model is suitable for control design and compatible with classical model of IM where the slotting effects are neglected $L_{h}=0$. Frequency speed $p \Omega_{r}$ may be done from mechanical torque filter.

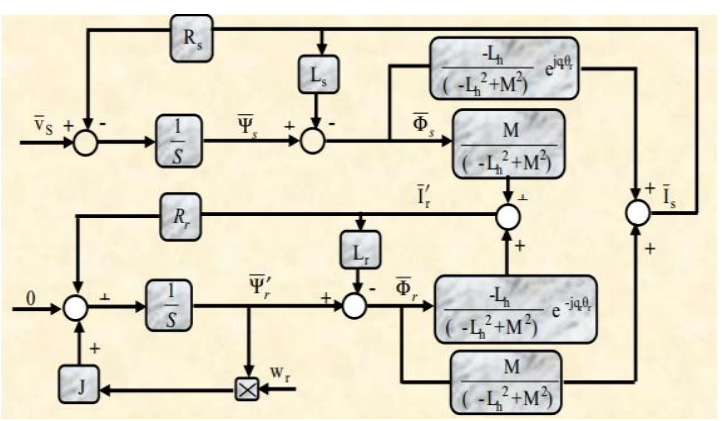

Fig. 1. Block presentation of induction machine model including rotor slotting effects for $\left(q_{r}=3 n-1\right)$

\section{Rotor Slotting Harmonics for Rotor Speed Detection}

In IM spectrum analysis many harmonics are located in air gap, the stator frequency as a fundamental harmonic is very dominant. Also, there are others harmonics which due to the eccentricity static or dynamic of rotor and to the power supply and rotor slotting. In general case, the air gap harmonics expression is given by [9]:

$$
f_{h}=\left[\left(k q_{r} \pm \frac{n_{d}}{p}\right)(1-s) f_{s} \pm v f_{s}\right]
$$

Where,

$$
\begin{aligned}
& f_{s}: \text { Stator fundamental frequency } \\
& k: \text { Positive integer } \\
& n_{d}=0, \pm 1 \ldots \text { Rotor eccentricity order } \\
& s: \text { per unit slip } \\
& v=1,3,5 \ldots \text { Stator Order of time harmonics present in } \\
& \text { power supply }
\end{aligned}
$$

We can be obtained the rotor slot harmonics when we consider the induction machine without eccentricity dynamic $\left(\mathrm{n}_{\mathrm{d}}=0\right)$, and taking into consideration only the fundamental harmonics of supply for $(v=1)$, also we consider just the fundamental rotor slot harmonics which corresponds to $k=1$. Hence the $\mathrm{RSH}$ (Rotor Slot Harmonic) is given by:

$$
f_{s h}=\left[q_{r}(1-s) f_{S} \pm f_{S}\right]
$$

The RSH can be detected by many ways such as measuring phase voltage, phase current or neutral point voltage [9], [12],[13].

Using (10), since supply frequency $f_{S}$ and $f_{s h}$ are known, the rotor speed in revolution per-minute (rpm) can be expressed by

$$
\Omega=\frac{60}{p} \frac{\left(f_{s h} \mp f_{s}\right)}{q_{r}}
$$

In literatures many researches used the real-time measurement of RSH by utilising spectral analysis techniques [10], however these techniques are not suitable for vector control application because they require long samples of data.

\section{Rotor Slotting Harmonics Detection Using HF Rotating Voltage}

The use of HF signal injection for tracking RSH presents a new challenge in estimation domain. As described in previous section add of $\mathrm{HF}$ signal to the fundamental excitation creates an additional harmonics in the resulting stator currents such harmonics were then used to monitor the rotor saliency produced by rotor slotting and therefore to calculate the position of rotor. Figure 2 shows the current spectrums obtained from the IM with $\left(q_{r}=14\right)$, operated at no load.



(a)



(b)

Fig. 2. Spectrum analyze of the stator current (a): without HF signal injection, (b): with HF signal injection 


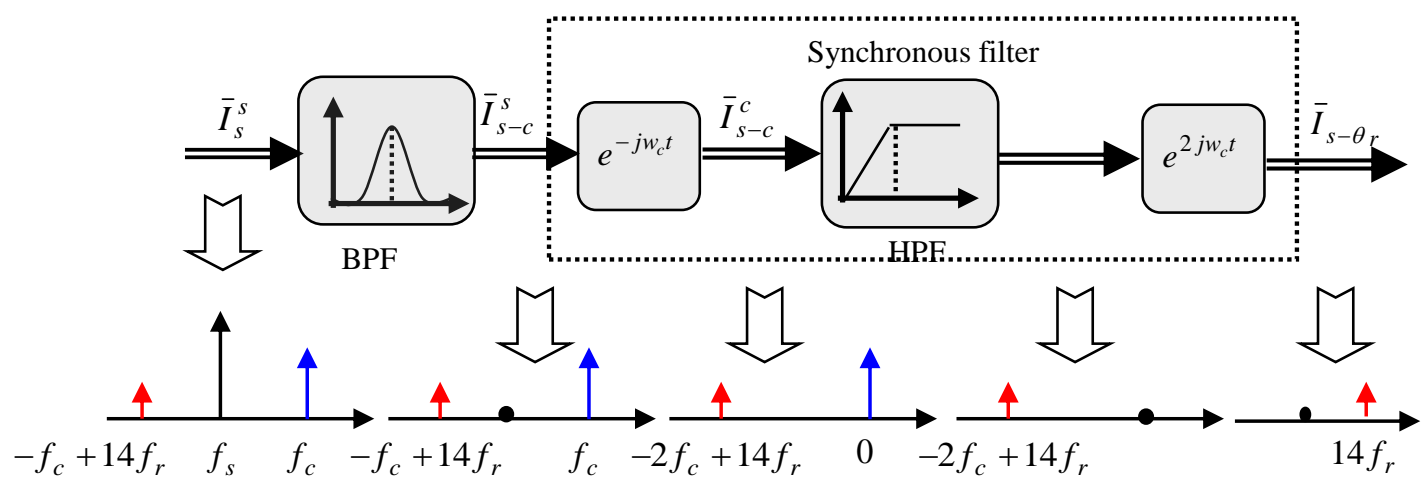

Fig. 3. Block diagram of the signal processing of the measured stator current for extraction position signal

From figure 2(a), we can observe that there is three dominate harmonics located at the following frequencies $5 \mathrm{~Hz}, 65 \mathrm{~Hz}$ and $75 \mathrm{~Hz}$. First one presents a fundamental supply frequency and the two second harmonics correspond to RSH, note that their amplitudes are very less than the fundamental one. RSH1 and RSH2 can be calculated from (10). As has been mentioned in [14], the RSH2 harmonic is not present for the balanced three phases winding, so it is preferable to use the RSH1 space harmonic for rotor speed detection. While RSH1 is detected in the current line, this proves the presence of rotor slotting effects (rotor saliency) and so that confirms the accuracy and goodness of the proposed saliencies Park model.

The spectrum of stator current obtained from the injection of HF rotating voltage $\left(20 \mathrm{~V}_{\mathrm{rms}}, 500 \mathrm{~Hz}\right)$ to the fundamental voltage supply $\left(27.5 \mathrm{~V}_{\mathrm{rms}}, 5 \mathrm{~Hz}\right)$ is shown in figure 2 (b). It can be observed that the frequency spectrum characterized by two additional harmonics located at the following frequencies $f_{1}=430 \mathrm{~Hz}$ and $f_{2}=500 \mathrm{~Hz}$. First one correspond to RSH modulated by HF (negative sequence component) pulsates at $w_{c}-14 p \Omega_{r}$ while the second one presents HF signal injection component (positive sequence component). Existing of the first component signifies that the HF signal injection tracked the saliency present in the machine. In our study this component will be utilised for rotor position detection.

The carrier signal current equation is given by (4). To extract the rotor position from it, we must pass by two steps. First step concerns the filtering process to eliminate undesirable components and leaves the component which contains the rotor position in its phase. Second step corresponds to the rotor position estimation will be done from the following methods: arcus-tangent function [15], PLL (Phase Locked Loop)[16] and tracking observer [12]. From (4) it can observe that the rotor position information existed in negative sequence current component then to obtain the rotor position it is sufficient to transform the carrier signal current to the positive sequence reference frame which rotates in opposite direction of positive sequence current component.

To extract the signal position (which contains the rotor position) the measured stator current treads to the filtering process. Block diagram of the signal processing of the measured stator current is presented in figure 3. In this diagram the BPF (band pass filter) used to filtering off the fundamental current component while leaves the carrier signal current. To eliminate the positive sequence current component, the carrier signal current is then transformed to the positive sequence reference frame, the positive sequence component becomes DC component whereas the negative sequence component rotates at $-2 w_{c}$. Eliminating the DC component the resulting current treads to HPF (high pass filter) after that the obtained current is transformed to the negative sequence reference frame which rotates at $2 w_{c}$, as consequence of the obtained signal position $\overline{\mathrm{I}}_{\mathrm{s}-\theta_{\mathrm{r}}}$.

To extract the rotor position contains in phase of $\overline{\mathrm{I}}_{\mathrm{s}-\theta_{\mathrm{r}}}$ a closed-loop tracking observer can be used as shown in figure 4 . This observer is used to calculate the error signal by taking the vector cross-product between the estimated signal positions and the measured one, in order to obligate the convergence of the estimated phase from measured phase.

$$
\varepsilon=\hat{\bar{I}}_{s-\theta_{r}} \times \bar{I}_{s-\theta_{r}}=I_{C n} \sin \left(14\left(\theta_{r}-\hat{\theta}_{r}\right)\right)
$$

where,

$\overline{\mathrm{I}}_{\mathrm{s}-\theta_{\mathrm{r}}}$ is the measured signal position and $\hat{\overline{\mathrm{I}}}_{\mathrm{s}-\theta_{\mathrm{r}}}$ is the estimated signal position.

Note that the error signal drives the controller which feeds the mechanical model based on the produced torque. This last, after mechanical integration, provides the estimate speed and after second integration the estimate rotor position.

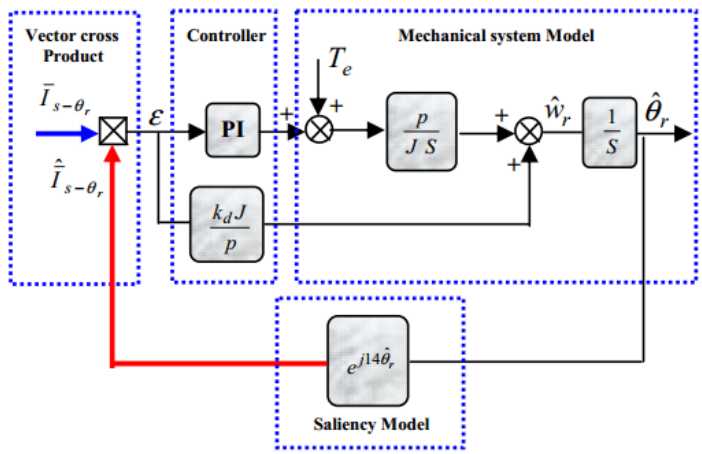

Fig.4. Schematic of tracking observer using for rotor position estimation 


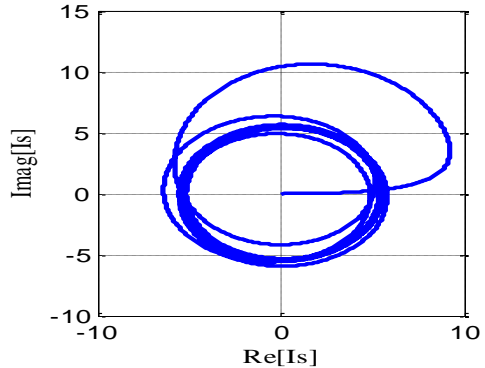

(a)

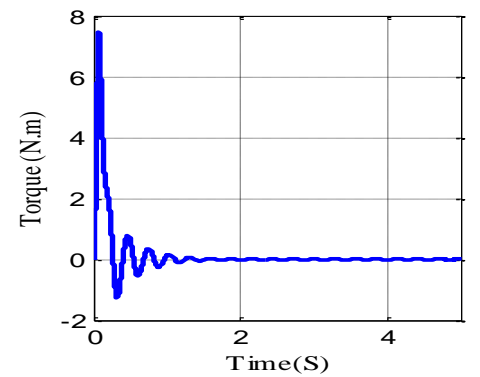

(b)

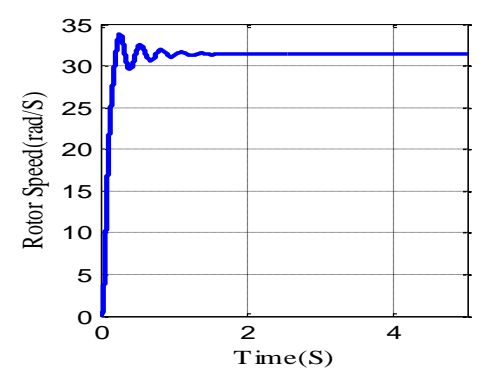

(c)

Fig.5. Healthy IM without saliencies and $\mathrm{HF}$ signal iniection

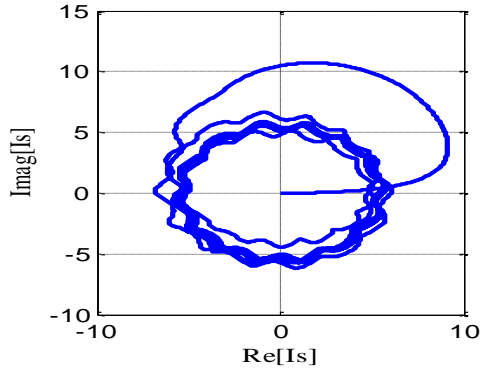

(a)

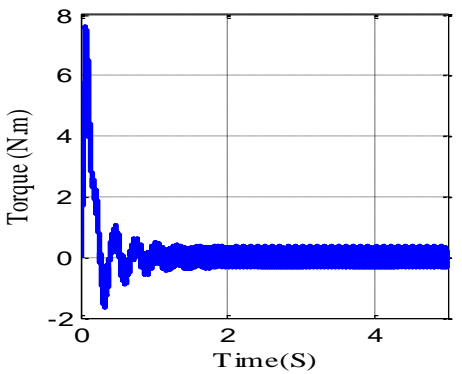

(b)

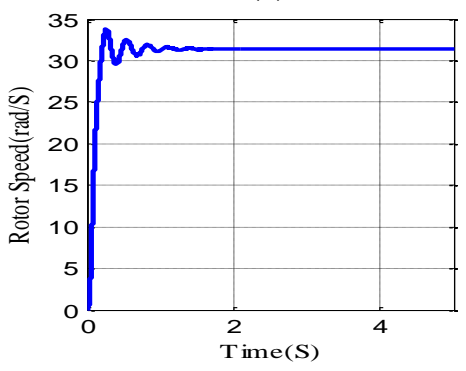

(c)

Fig.6. IM with saliencies and without HF signal injection

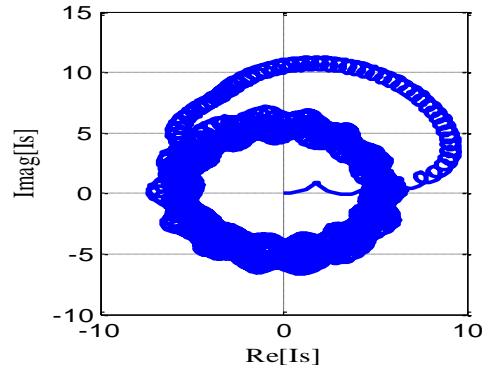

(a)

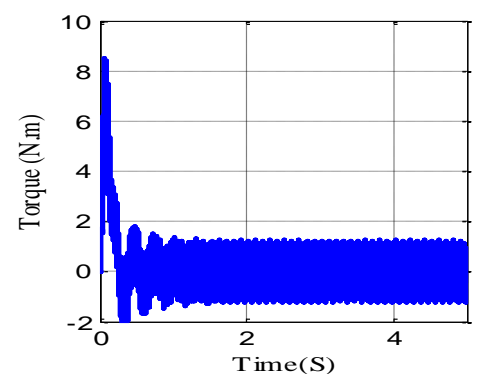

(b)

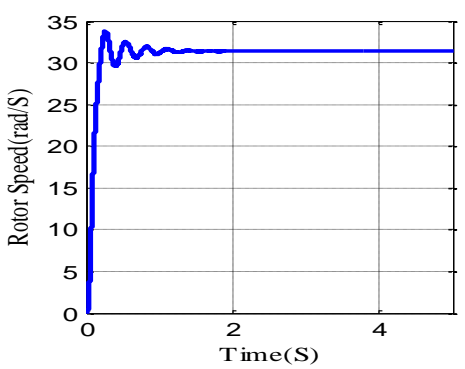

(c)

Fig. 7. IM with saliencies and HF signal injection

\section{Simulation Results}

The used induction machine for simulation has parameters given in Table I. It operates at no load and feeds by $\left(27.5 \mathrm{~V}_{\mathrm{rms}}, 5 \mathrm{~Hz}\right)$ as a fundamental voltage supply.

\section{A. IM-Simulation with rotor slotting effects and without HF signal injection}

To show the affects of the rotor slotting on the performance of IM the proposed model is simulated without injecting HF signal with presence of rotor slotting effects $\left(L_{h}=7.5000 \mathrm{e}-004 \mathrm{H}\right)$. The obtained responses are shown in figure 6 . From figure 6(a), we can observe that the presence of rotor slotting effects appearing clearly in stator current trajectory which have not a circular form as stator current trajectory without rotor slotting at figure 5(a). It presents the lobes caused by the rotor slotting effects. This deformation appeared in current spectrum, figure 2(a), as an additional component presenting $\mathrm{RSH}$. The rotor speed response is depicted in figure 6 (b), it shown a good performance of IM, even if it presents a ripple around steady state. The electromagnetic torque figure 6(c) is also characterized by the presence of ripples in steady state regime. These last do not appear in response of electromagnetic torque without slotting effects as shown in figure 5(c).
These oscillations are due to the rotor flux linkage which affected by the rotor slotting effects. The obtained simulation results proves correctly the effects produced by rotor slotting, which sustained the accuracy and goodness of the proposed model, moreover this model is compatible for IM without rotor slotting effects.

\section{B. IM-Simulation including rotor slotting effects with HF signal injection}

To test the performance of induction machine supplied by high frequency signal, and to prove the capability of injected signal to track the rotor position, a simulation test is applied on the same IM (parameters given in Table 1). It supplied by high frequency rotating voltage $\left(20 \mathrm{~V}_{\mathrm{rms}}, 500 \mathrm{~Hz}\right)$ superimposed to its fundamental supply $\left(27.5 \mathrm{~V}_{\mathrm{rms}}, 5 \mathrm{~Hz}\right)$.

The additional HF rotating voltage generates HF field interacts with the main field. This interaction creates an additional harmonics in both stator current and flux responses. The spectrum of stator current has been shown in figure 2(b). As the machine is assumed that it contained only a single saliency (rotor saliency), the additional component in stator current spectrum is RSH modulated by high frequency. 


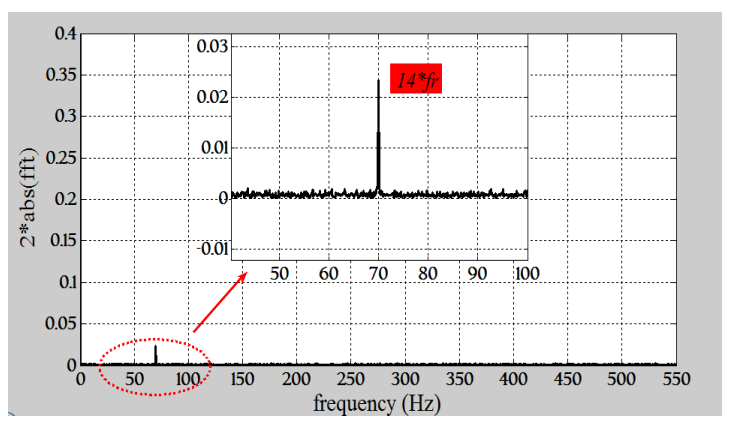

Fig. 8. Spectrum of signal position $I_{s \alpha-\theta_{r}}$

This additional harmonic has an influence on the trajectory of stator current which depicted in figure 7(a). However, the added signal has no detectable effect on the behaviour of rotor speed, as shown in figure 7(b), for the reason of rotor inertia filtered effect. The IM reacts to injected signal by a ripple appears in electromagnetic curve, see figure 7(c). As described in a previous section the HF injection able to track the rotor position located in stator current. This can be extracted by filtering the resulting stator current, as illustrated in figure 3 . The spectrum of obtained signal position is shown in figure 8 . From that figure it can be seen that there is only the harmonic located at $14 f_{r}$, this harmonic contains the rotor frequency information which will be extracted by tracking observer. Capability of tracking observer to estimate the rotor position confirms the effectiveness of estimation method at zero frequency using tests simulation. Going to zero speed estimation, the speed command has been changed from $31.4 \mathrm{rad} / \mathrm{S}$ to $0 \mathrm{rad} / \mathrm{S}$ as shown in figure 9. This test confirms that without rotor saliencies effect the zero speed estimation cannot obtain, this is considered as challenge in domain of robust speed estimation.

\section{Conclusion}

In this paper a new model including rotor slotting effects was proposed. This one might be suitable for some control applications. The rotor saliency produced by slotting effects has many advantageous than the other saliency which required the essential modification in machine design. For tracking the rotor saliency, the HF persistent voltage excitation is used. This excitation was superimposed to fundamental supply of induction machine. The interaction between the high frequency excitation and the saliency presented in the machine created a new additional harmonic appeared in measured stator current. This harmonic was useful for rotor speed estimation, after filtering the other undesirable harmonics. A tracking observer provides a simple and robust way to extract the rotor spatial information present in position signal. According to the presented simulations results, we can conclude that the proposed saliencies Park model was able to describe the rotor slotting effects in induction machine. Using introduced HF rotating voltage allows marking the tracking saliency due to the rotor slotting and therefore both speed and position of the rotor may be determined. Combination between the slotting effect and

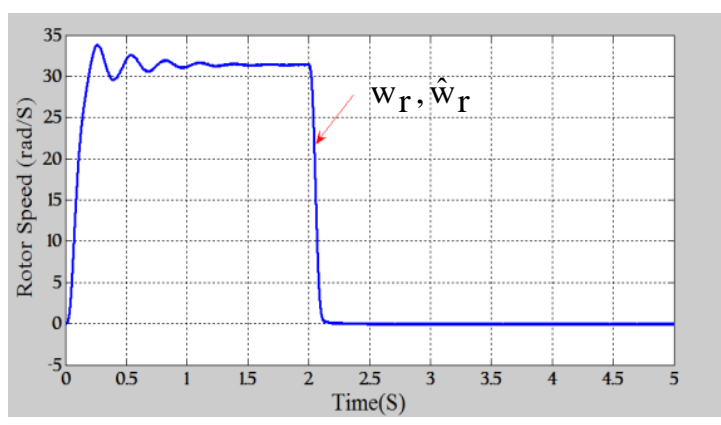

Fig. 9. Real and estimated rotor speed with HF signal injection

the use of HF signal injection makes injection makes the estimation method as very robust over a wide speed range including lower and zero speeds estimation, generally very difficult to obtain it by the analytical model methods.

Table I. - Induction Machine Data

\begin{tabular}{|l|c|l|c|}
\hline $\begin{array}{c}\text { MACHINE } \\
\text { PARAMETERS }\end{array}$ & VALUE & $\begin{array}{c}\text { MACHINE } \\
\text { PARAMETERS }\end{array}$ & VALUE \\
\hline Rated voltage & $\begin{array}{c}220 / 380 \\
\mathrm{~V}\end{array}$ & $\begin{array}{l}\text { Speed and stator } \\
\text { frequency }\end{array}$ & $\begin{array}{c}1485 \mathrm{rpm} \\
50 \mathrm{~Hz}\end{array}$ \\
\hline Rated Power & $4 \mathrm{~kW}$ & $L_{s}$ & $0.1568 \mathrm{H}$ \\
\hline Poles number & 4 & $L_{r}$ & $0.1568 \mathrm{H}$ \\
\hline$R_{s}$ & $1.2 \Omega$ & $M$ & $0.1500 \mathrm{H}$ \\
\hline$R_{r}$ & $1.8 \Omega$ & $J$ & $0.05 \mathrm{kgm}$ \\
\hline$N_{r}$ & 28 & $N_{s}$ & 36 \\
\hline
\end{tabular}

\section{Acknowledgement}

This research has been realized in cooperation of the University of Batna Department of Electrotechnical Engineering, Batna, Algeria, LSPIE Laboratory.

\section{References}

[1] F. BRIZ and M. W. Degner,"A Review of High Frequency Methods",IEEE Industrial electronics magazine ,May/June 2011, pp. 24-36.

[2] T.M. Wolbank, M.K. Metwally, "Separation of Saliency Components for Speed Sensorless Detection of Flux and Rotor Position of Induction Machines", Proceedings of the 2008 International Conference on Electrical Machines, 9781-4244-1736.

[3] S.Nandi, "Modeling of induction machines including stator and rotor slot effects", IEEE Trans,Ind,Appl,vol.40 ,n.4,July./Aug.2004,pp.1058- 1065.

[4] S.Nandi, "Slot permeance effects on rotor slot harmonics in induction machines", IEEE Electric Machines and Drives Conference 2003, IEMDC'03,vol.3,1-4June 2003,pp.16331639.

[5] M.W.Degner and R.D.Lorenz,"Position estimation in induction machines utilizing rotor bar slot harmonics and carrier frequency signal injection",IEEE Trans, ,Ind,Appl.,vol.36,no.3,May/Jun. 2000.pp. 736-742. 
[6] F.Briz, M.W.Degner,P.Garcia,R.D.Lorenz, "Comparison of saliency-based sensorless control techniques for ACmachines",IEEETrans,Ind,Appl.,vol.40,no.4,Jul./Aug20 04.pp. 1107-1115.

[7] Q.Gao, G.M.Asher, M.Summer, "Sensorless Position and Speed Control of induction Motors Using High Frequency Injection Without Offline Percommissioning",IEEE Trans,Ind,Appl.,vol.54,Oct. 2007.pp. 2474-2481.

[8] L. A. S. Ribeiro ,M. W. Degner, F. Briz, R.D. Lorenz, "Comparison of carrier signal voltage and current injection for the estimation of flux angle or rotor position", Proceeding of IEEE-IAS 1998 Annual Meeting, vol. 1, Oct. 1998. pp. 452- 459.

[9] O.Keysan and H.B.Ertan,"Higher Order Rotor slot Harmonics for Rotor Speed \& Position Estimation", Optimization of Electrical and Electronic Equipment,Brasov,2010.

[10] R.Blasco-Gimennez,G.M.Asher and M.Sumner ,K.J.Bradley, "Performance of FFT-rotor slot harmonic speed detector for sensorless induction motor drives ", IEE Proc-ElectrpowerAppl., vol.143,no.3, May 1996.PP. 258260.

[11] M.Cirrincione, M.Pucci, G.Cirrincione, A.Miraoui, "SpaceVector State Model of Induction Machines Including Rotor Slotting Effects: Toward a New Category of Observers",IEEETrans,Ind,Appl.,vol.44,n.6,Nov./Dec. 2008.

[12] F.Briz, W.Degner, P.Garcia,and J.M.Guerrero, "Rotor position estimation of AC machines using the zerosequence carrier-signalvoltage",IEEE Trans, Ind,Appl.,vol.41,n.6,Nov./Dec.2005.pp. 1637-1646.

[13] F.Briz, M.W.Degner, P.Garcia and A.B.Diez, "Rotor and Flux Position Estimation in Delta-Connected AC Machines Using the Zero-Sequence Carrier-Signal Current", IEEE Trans, Ind,Appl., vol.42, n.2,March./April. 2006.pp. 495-503.

[14] S.Nandi,H.Toliyat,"NovelFrequency-Domain-Based Technique to Detect Stator Interturn Faults in Induction Machines Using Stator-Induced Voltages After Switch-Off ",IEEETrans,Ind,Appl.,vol.38,n.1,January/February2002.pp .101-109.

[15] C.S.Staines,G.M.Asher, M.Sumner, "Rotor-position Estimation for Induction Machines at Zero and Low Frequency Utilizing Zero-Sequence Currents",IEEE Trans,Ind,Appl., vol. 42, n. 1, 2006.pp. 105-112.

[16] C.Caruana, G.M.Asher, K.J.Bradley ,M.Woolfon,"Flux Position Estimation in Cage Induction Machines Using Synchronous HF Injection and Kalman Filtering", IEEETrans,Ind,Appl., vol. 39, n. 5, 2003.pp. 1372-1378. 